University of Nebraska - Lincoln

DigitalCommons@University of Nebraska - Lincoln

Effects on the Function of Three Trophic Levels in Marine

Plankton Communities under Stress from the Antifouling Compound Zinc Pyrithione

\author{
M. Hjorth \\ National Environmental Research Institute, Roskilde, Denmark \\ I. Dahllöf \\ National Environmental Research Institute, Roskilde, Denmark \\ Valery E. Forbes \\ University of Nebraska - Lincoln, veforbes@umn.edu
}

Follow this and additional works at: https://digitalcommons.unl.edu/biosciforbes

Part of the Pharmacology, Toxicology and Environmental Health Commons

Hjorth, M.; Dahllöf, I.; and Forbes, Valery E., "Effects on the Function of Three Trophic Levels in Marine Plankton Communities under Stress from the Antifouling Compound Zinc Pyrithione" (2006). Valery Forbes Publications. 44.

https://digitalcommons.unl.edu/biosciforbes/44

This Article is brought to you for free and open access by the Papers in the Biological Sciences at DigitalCommons@University of Nebraska - Lincoln. It has been accepted for inclusion in Valery Forbes Publications by an authorized administrator of DigitalCommons@University of Nebraska - Lincoln. 


\title{
Effects on the Function of Three Trophic Levels in Marine Plankton Communities under Stress from the Antifouling Compound Zinc Pyrithione
}

\author{
M. Hjorth ${ }^{\mathrm{a}, \mathrm{b}}$, I. Dahllöf ${ }^{\mathrm{a},{ }^{*},}$ V.E. Forbes ${ }^{\mathrm{b}}$

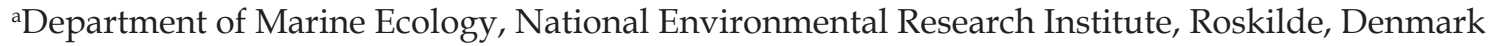 \\ ' Institute of Biology, University of Roskilde, Roskilde, Denmark \\ *Corresponding author: ind@dmu.dk.
}

Received June 26, 2005; received in revised form November 14, 2005; accepted November 16, 2005.

\begin{abstract}
This study aimed to investigate functional responses of natural marine planktonic communities to stress from the antifouling compound zinc pyrithione (ZPT). Isotope labelling techniques $\left({ }^{14} \mathrm{C}\right)$ were applied to study bacterial incorporation of leucine, photosynthetic activity of phytoplankton and grazing of labelled prey by zooplankton communities for 6 days after exposures to nominal concentrations of $0,5,25,50 \mathrm{nM}$ ZPT in a mesocosm experiment in Isefjord, Denmark.

Significant direct effects were visible on chlorophyll a concentrations, which decreased in all exposed communities, to between 48 and 36\% of control concentrations on Day 3, 1 day after the last exposure. Phytoplankton activities were also significantly affected on Day 3 with activities between 9 and $26 \%$ of control levels, as was zooplankton activities in the 25 and $50 \mathrm{nM}$ exposures. In the $50 \mathrm{nM}$ exposure the total community zooplankton activity was reduced to $25 \pm 4 \%$, and per individual to $46 \pm 11 \%$ of control levels. Bacterial communities showed positive indirect effects with high activities (up to $183 \pm 40 \%$ ) due to higher amounts of available substrate from algal death. Pollution induced community tolerance analyses performed on phytoplankton and bacterial communities at the end of the experiment indicated a development of increased tolerance for phytoplankton in the $50 \mathrm{nM}$ exposed communities, whereas there were no changes in tolerance in the bacterial communities. Multivariate analysis of the integrated functional response by the plankton communities revealed a significant difference $(p<0.05)$ between exposed communities compared to controls in the first 3 days after last exposure and in the end of the experiment. The study provides evidence of diverse effects on the functions of marine plankton communities under stress from a pollutant. Direct effects lead to cascading indirect effects throughout the community, eventually causing different developments. Continuous exposure to ZPT could lead to severe long-term effects, causing more permanent changes in structure and function than observed here. The study demonstrates that it is possible to assess the functional effects of a stressor in a complex mesocosm system, and to determine effects in a complex plankton community, which were not predictable from laboratory studies.
\end{abstract}

Keywords: Functional response, Stress, Plankton, Natural communities, PICT, Indirect effects

\section{Introduction}

The marine plankton ecosystem is the foundation of almost all organic matter production in the sea, which means that changes in this system may potentially affect the marine ecosystem as a whole. Changes can be induced through factors that stress the ecosystem, at the community, population or individual organism level. Factors causing stress may be changes in environmental factors such as light, nutrients, salinity and temperature, competition and/or predation between trophic levels and anthropogenic factors such as exposure to pollutants. The issue of stress induced changes and their effects have been studied intensively both using one or several stress factors together (Fleeger et al.,
2003; Paerl et al., 2002; Calow and Forbes, 1998). However, most studies at the population and community level using mesocosms have mainly considered effects on community structure, such as abundance and diversity of selected organism groups, and have not as frequently taken effects on the functions of a community into consideration (Møhlenberg et al., 2001). Furthermore, analysis of indirect effects inherently requires studies of populations, communities or whole ecosystems (Fleeger et al., 2003; Preston, 2002).

So far, few studies have been made of stress responses of the marine planktonic ecosystem that include the function of several trophic levels, and direct as well as indirect effects. Such studies also give the opportuni- 
ty to integrate the effects on a pelagic community lev$\mathrm{el}$, that is comparing the function of all components simultaneously, providing an assessment of changes to the functional pattern thereby including the interactions between the single components (Dahllöf et al., 1999). The objective of this study was to estimate the impact of a toxicant on the function of a marine plankton ecosystem and to determine the extent to which indirect effects from the stressor influence the subsequent development of the communities. To estimate whether the stressor also induces more long-term effects, such as selecting for a more tolerant community, a pollution induced community tolerance (PICT) study (Blanck et al., 1988) was performed at the end of the experiment.

The stressor of choice in this study was a recently introduced antifouling compound zinc pyrithione (ZPT), and the results contributed to assessing the risks of this compound to the marine environment (Dahllöf et al., 2005). Fouling is an ever-present problem for commercial shipping as well as recreational sailing. The dilemma between targeting and eliminating fouling organisms on ship hulls with the use of biocides without harming the remaining marine environment, remains unsolved. The ban of tri- $n$-butyl tin (TBT) as an active compound in ship paints has led to developments of second and third generations of products supposedly less harmful to the marine environment, one of which is zinc pyrithione. ZPT is an organo-metal complex, in which the zinc ion is complexbound to two pyrithione groups. Studies on the fate of ZPT in seawater have shown that approximately half of the nominal concentration added is transformed to copper pyrithione, while the other half is transformed to other unidentified complexes depending on the availability of other ligands in the water (Grunnet and Dahllöf, 2005). So far, only one attempt of measuring ZPT in the marine environment has been reported using a method with a detection limit of $20 \mathrm{ng} / 1$ (Thomas, 1999). In that study a water sample from a marina was analysed, but no ZPT was detected. Pyrithione, the ligand in $\mathrm{ZPT}$, has also been measured in one study (Mackie et al., 2004), where concentrations up to $105 \pm 5 \mathrm{nM}$ were detected in the Mercy River, UK, corresponding to $\sim 50 \mathrm{nM} \mathrm{ZPT}$ if all the pyrithione originated from ZPT. The effects on natural phytoplankton communities from Danish waters have been studied, giving EC50 values in the range 2-60 nM nominal concentration (Maraldo and Dahllöf, 2004b). The variation in EC50 could partly be explained by differences in community composition and availability of phosphate.

This study was designed to mimic a scenario in which a small group of leisure boats anchors in a shallow part of a Danish fjord every night for a period of 3 days. The hulls of the boats are treated with antifouling paint with the active biocide ZPT that is slowly released to the water body under and around the boats. The scenario represents a reality that occurs frequently during spring to autumn all along the Danish coastline. Direct and indirect impacts of the released ZPT on the pelagic community, as well as the duration of the impact were then followed during 8 days. Through the use of standard techniques, newly designed protocols for zooplankton grazing measurements and state of the art molecular methods, this mesocosm study presents valuable information on how stress from a selected pollutant influences the function and structure of a marine plankton ecosystem.

\section{Materials and methods}

\subsection{Design}

The mesocosm experiment was carried out in the Isefjord, Denmark (average depth 5-7 m), for 8 days in June 2003. Twelve clear polyethylene cylindrical enclosures $(2.5 \mathrm{~m}$ deep, $1.25 \mathrm{~m}$ in diameter, with $0.1 \mathrm{~mm}$ thick walls, volume approximately $3 \mathrm{~m} 3$ ) were filled with adjacent fjord water. The pelagic enclosures were attached to a pontoon bridge in the fjord placed $200 \mathrm{~m}$ from the shore at a depth of $4 \mathrm{~m}$. On the same day as the bags were filled, and for the next two consecutive days, a nominal concentration range of 0 (solvent only) 5,25 and $50 \mathrm{nM} \mathrm{ZPT}$ was added to the bags $(n=3)$. The addition of ZPT to the bags took place under intense stirring and after nightfall to avoid photodegradation of ZPT. Zinc pyrithione (bis(1-hydroxy2[1H]-pyridinethionato-O-S)-(T4)zinc) or zinc omadine ${ }^{\circledR}$ )was supplied by Arch Chemicals (Norwark, USA) and $0.048 \mathrm{~g}$ was dissolved in $100 \mathrm{ml}$ dimethylsulphoxide (DMSO) (Merck, Darmstadt, Germany) to yield a stock solution of $1.5 \mathrm{mmol} / \mathrm{l}$. A volume of $100 \mathrm{ml}$ stock solution was added to the $50 \mathrm{nM}$ treated bags, and $100 \mathrm{ml}$ two and ten times dilutions of the stock solution was added to the 25 and $5 \mathrm{nM}$ treated bags, respectively and $100 \mathrm{ml}$ DMSO alone to the control bags. The solvent concentration did not exceed $37 \mathrm{mg} / \mathrm{l}$ in any of the bags. The range of exposure concentrations was chosen on the basis of previous results from dose response experiments on natural phytoplankton and bacterial communities (Maraldo and Dahllöf, 2004a,b). During the 3 days of ZPT addition, water samples from the $50 \mathrm{nM}$ addition were taken for chemical analysis of the fate and degradation of the compound (Grunnet and Dahllöf, 2005). After the 3 days of consecutive pulse exposure, vertical water samples were taken daily from each bag for analyses of the selected variables for 6 days. On the last day pollution induced community tolerance (PICT) experiments were performed for two bags from each addition, with bacterial and phytoplankton activities as targeted variables. 


\subsection{Sampling}

Two sets of depth integrated water samples were taken with a $2.0 \mathrm{~m}$ long PVC tube (diameter: $7 \mathrm{~cm}$ ) at two separate times in the morning of each day, with a maximum $2 \mathrm{~h}$ interval, and each set consisting of $2 \times 81$ per bag. In total 2,241 of water were sampled from the mesocosm bags during the whole experiment, which amounts to $7.5 \%$ of the total volume. Sample water from both sets were gently filtered through a $45 \mu \mathrm{m}$ sieve to collect larger zooplankton. From the first set of samples, the collected zooplankton were used for analyses of grazing potential. At 2-day intervals in the 0 and $50 \mathrm{nM} \mathrm{ZPT} \mathrm{mesocosm} \mathrm{bags,} \mathrm{were} \mathrm{the} \mathrm{diversity} \mathrm{and}$ abundance of copepods estimated from the second set of samples. The zooplankton were concentrated on a $45 \mu \mathrm{m}$ filter and fixed in Lugol. Samples were analysed for total abundance of copepods (adult individuals/1) in Utermöhl chambers using an Olympus CK40 inverted microscope with 100-200× magnification. A minimum of 50-100 ml subsample was counted, or at least 100 individuals. Adult copepods and copepodites were pooled as one group.

From the first set of samples, subsamples of 51 were taken immediately ashore for all other analyses, and the remaining 111 was discarded. Surface salinity and temperature were measured with a Leica Refractometer (Reichert Instruments, Germany) and a standard thermometer, respectively, in all bags during the first sampling time.

Chlorophyll a and nutrients were measured on Day 0 before the first ZPT addition. Chlorophyll a was also measured on Days 1 and 2, whereas nutrients and all other variables were measured daily from Day 3. The phytoplankton biomass was determined as the concentration of chlorophyll $a$ in a $50 \mathrm{ml}$ sample vacuum-filtered through a GF/F filter, and extracted in $5 \mathrm{ml} 96 \%$ ethanol for $24 \mathrm{~h}$ and thereafter fluorometrically analysed (10-AU Turner fluorometer, USA).

Thirty milliliters of water from each bag was kept frozen until analysis of $\mathrm{SiO}_{2}^{2-}, \mathrm{HPO}_{4}^{2-}, \mathrm{NH}_{4}^{+}$and $\mathrm{NO}_{3}^{-}+\mathrm{NO}_{2}^{-}$ . The analyses were performed on a Skalar autoanalyser according to recommendations from the Danish Marine Monitoring Program (Andersen et al., 2004).

Bacterial diversity was estimated in 22 selected samples by DNA extraction, PCR amplification using the $r p o B$ gene followed by DGGE separation as described by Petersen et al. (2004).

\subsection{Bacterial activity}

The functional response of the bacterial community was monitored as protein synthesis activity by daily measurements of ${ }^{14} \mathrm{C}$-labelled leucine incorporation, where a modified version of Smith and Azam's (1992) centrifugation $\left({ }^{14} \mathrm{C}\right)$-leucine-incorporation method was applied. From each mesocosm four subsamples of $1 \mathrm{ml}$ were transferred to a $2 \mathrm{ml}$ Eppendorf tube and $50 \mu \mathrm{l}$ of $4 \mathrm{mM}\left[{ }^{14} \mathrm{C}\right]-1$-leucine $\left(295 \mathrm{mCi} \mathrm{mmol}^{-1}\right.$, Amersham, Life Science) was added to achieve a final concentration of $190 \mathrm{nM}$ in each tube. Blind samples were prepared with $100 \mu 100 \%$ trichloroacetic acid (TCA) in $1 \mathrm{ml}$ water and run in parallel in order to estimate the magnitude of abiotic leucine adhesion, as well as to control for contamination of the leucine solution. All samples were incubated for $60 \mathrm{~min}$, and thereafter 100 $\mu \mathrm{l}$ of cold $100 \%$ TCA and $15 \mu \mathrm{l}$ of skim milk were added to lyse cells and enhance the precipitation of protein. The samples were stored at $5^{\circ} \mathrm{C}$ until centrifugation and washing with TCA. The samples were centrifuged for $10 \mathrm{~min}$ at $13,000 \times g$ and $4^{\circ} \mathrm{C}$, the supernatant was removed, $1 \mathrm{ml}$ of $100 \%$ TCA was added and the sample was vortexed. Thereafter the samples were centrifuged for another $10 \mathrm{~min}$ at $13,000 \times \mathrm{g}$ and $4^{\circ} \mathrm{C}$. Finally, the supernatant was removed, $1 \mathrm{ml}$ of Ecoscint A (National Diagnostics, Atlanta, USA) was added and the tubes were vortexed again. After $24 \mathrm{~h}$ of storage at room temperature $\left(18^{\circ} \mathrm{C}\right)$, the samples were radioassayed in a Beckman LS 1801 scintillation counter. The mean value of the control mesocosm bags was set to $100 \%$ activity.

\subsection{Phytoplankton activity}

The functional variable of the phytoplankton was $\mathrm{H}^{14} \mathrm{CO}_{3}^{-}$incorporation as an estimate of primary production. From each mesocosm subsample, four replicates of $10 \mathrm{ml}$ were taken with a $10 \mathrm{ml}$ automatic kip dispenser pipette (Schott Duran, Mainz, Germany) and transferred to $20 \mathrm{ml}$ glass vials (BN Instruments, Denmark). Two microcurie of $\mathrm{H}^{14} \mathrm{CO}_{3}\left(1 \mathrm{mCi} / \mathrm{ml},{ }^{14} \mathrm{C}\right.$ Agency, Hørsholm, Denmark) were added to each sample and the samples were incubated for $2 \mathrm{~h}$ under cool white light (2× Pope FTD 18W/33, Holland). To examine for abiotic ${ }^{14} \mathrm{C}$ adhesion and bacterial incorporation of ${ }^{14} \mathrm{C}$, two dark samples were run in parallel with each experiment. Immediately after the incubation, $200 \mu \mathrm{l} \mathrm{M} \mathrm{HCl}$ was added to remove non-incorporated ${ }^{14} \mathrm{C}$ in the samples. After $24 \mathrm{~h}, 10 \mathrm{ml}$ of Insta-gel Plus (Perkin-Elmer Life and Analytical Sciences, Inc., Boston, USA) was added and the samples were stored for at least $24 \mathrm{~h}$ and at most for one week at room temperature. Finally, the samples were radioassayed in a Beckman LS 1801 scintillation counter. The total incorporation was measured as the amount of radiolabelled carbon, and all the samples were corrected for the amount of abiotic ${ }^{14} \mathrm{C}$ in the dark sample. Mean values of the triplicate control mesocosm bags were set to $100 \%$ activity.

\subsection{Zooplankton activity}

To estimate the functional response of the zooplankton community to the toxicant exposure, grazing rates 


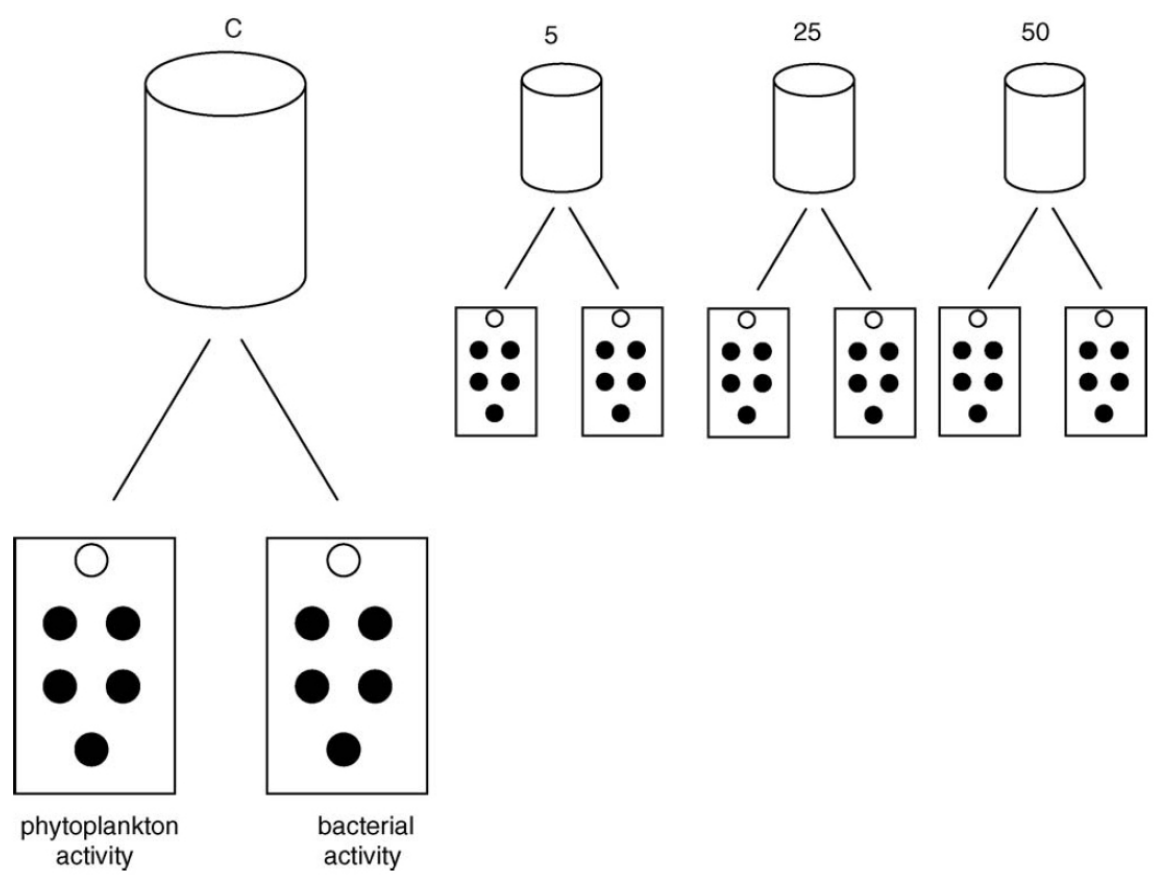

Figure 1. Experimental set-up for short-term toxicity tests used in the phytoplankton and bacteria PICT analysis. Pre-exposed communities from the mesocosm experiment were submitted to short-term toxicity tests. Each test consisted of new additions of five concentrations of ZPT $(\bullet)$ and one control (o).

were monitored daily during the experimental period by measurement of ${ }^{14} \mathrm{C}$ labelled prey uptake as described in detail in another manuscript (Hjorth et al., in press) Briefly, four $10 \mathrm{ml}$ replicates of representative zooplankton samples from each mesocosm bag were taken with a $5 \mathrm{ml}$ automatic kip dispenser pipette (Schott Duran, Mainz, Germany) and incubated with aliquots of ${ }^{14} \mathrm{C}$ labelled phytoplankton previously prepared. One day prior to the experiment, a phytoplankton sample was taken at the same site and incubated with $\mathrm{H}^{14} \mathrm{CO}_{3}$ for $24 \mathrm{~h}$. It was then concentrated to yield an activity of approximately $1,500 \mathrm{dpm} / \mathrm{ml}$ and split into 6-day portions and kept at $-18^{\circ} \mathrm{C}$ until use. Zooplanktons were allowed to feed on the labelled prey for $1 \mathrm{~h}$ and were then rinsed with $0.2 \mathrm{~m}$ filtered seawater and collected on $45 \mu \mathrm{m}$ filters. The filters were transferred to plastic scintillation vials, $3 \mathrm{ml}$ of Ecoscint A (National Diagnostics, Atlanta, USA) was added and the samples were radioassayed in a Beckman LS 1801 scintillation counter.

\subsection{PICT analyses}

Six days after the last addition of ZPT, PICT studies were carried out on selected mesocosm bags with phytoplankton and bacterial activity as variables. Shortterm dose-response experiments were performed for each level of the ZPT pre-exposed communities (Figure 1). Subsamples of duplicate bags of each treatment were exposed for $1 \mathrm{~h}$ in four replicates to $0,5,25,50$, 100 and $200 \mathrm{nM}$ of ZPT, after which they were incubated with ${ }^{14} \mathrm{C}$ labelled leucine $(1 \mathrm{~h})$ and $\mathrm{H}^{14} \mathrm{CO}_{3}(2 \mathrm{~h})$, and subsequently handled according to the procedures described above.

\subsection{ZPT/CPT analysis}

The extraction and analysis were performed according to Grunnet and Dahllöf (2005) and are briefly described below. Samples with added internal standard were extracted using solid-phase extraction (SPE) cartridges (Strata X, $6 \mathrm{ml}, 200 \mathrm{mg}$ polymeric sorbent packing, Strata) immediately after sampling. ZPT and CPT were extracted from the columns using a 70:20:10 mix of acetonitrile, methanol and deionised water. Chromatography was performed on an HPLC-system with UV-vis-Diode Array (Hewlett Packard Series 1100). Simultaneous determination of zinc-and copper-pyrithione in seawater was performed on an HPLC-system equipped with an online degasser, a quaternary gradient pump, an automatic sample loop adjusted to $40 \mu \mathrm{l}$, a thermostable column compartment, and a UV-visDiode Array detector. The column was an end-capped C-18 Jupiter ( $99.99 \%$ metal-free) column, kept at $26^{\circ} \mathrm{C}$. The flow rate was kept at $1 \mathrm{ml} / \mathrm{min}$ at all times. ZPT was recorded at $270 \mathrm{~nm}, \mathrm{CPT}$ at $320 \mathrm{~nm}$, and the internal standard (Xylene cyanol) at $616 \mathrm{~nm}$.

\subsection{Statistical analysis}

For each functional variable, the data set consisted of mean values of each mesocosm bag from every day. Possible outliers were detected using Grubb's test (Grubbs and Beck, 1972) and if found significant $(p<$ $0.05)$ they were discarded, which only occurred on 10 


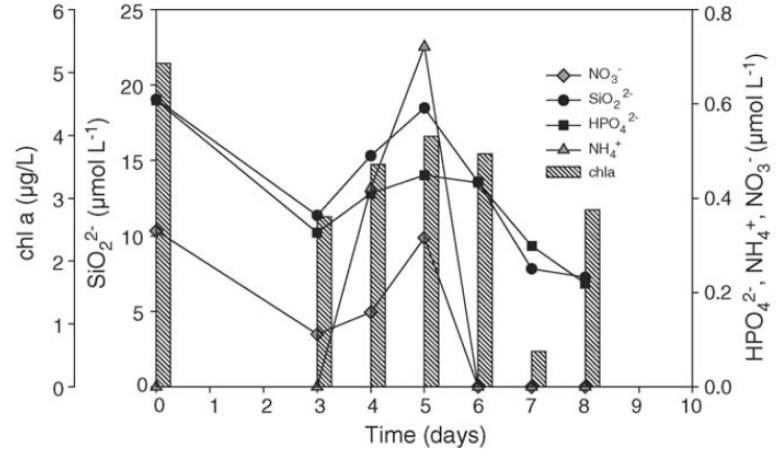

Figure 2. Means of chlorophyll a and inorganic nutrients in control communities during the course of the experiment.

occasions in the whole data set $(n=1,768)$. Differences between means of control and exposed communities, was tested in a two-way ANOVA with Dunnett's twotailed $t$-test as a post hoc test and was performed after testing for homogeneity of variances (Levene's test). Differences between days in control communities were tested with Dunnett's test, in which each day was tested for difference compared to Day 0. General trends in control communities were also tested by linear regression. All statistical analyses except multivariate analyses (see below) were done using SAS $\AA$ software (version V8.02). Data from the PICT analyses were analysed by calculating $\mathrm{EC}_{x x}$ values and standard deviations through the ICp approach (Norberg-King, 1993).

In order to determine differences between the integrated functional development of the exposed and control communities, functional responses were compared in a multivariate analysis using Primer version 5.0 (Plymouth Routines In Multivariate Ecological Research, PRIMER-E Ltd., Plymouth). The means of the three functional variables and their 95\% confidence limits of each exposure level for all days were standardized by the total means without transformations.

A Bray-Curtis similarity index (Bray and Curtis, 1957; Clarke and Warvick, 1994) was calculated from this set

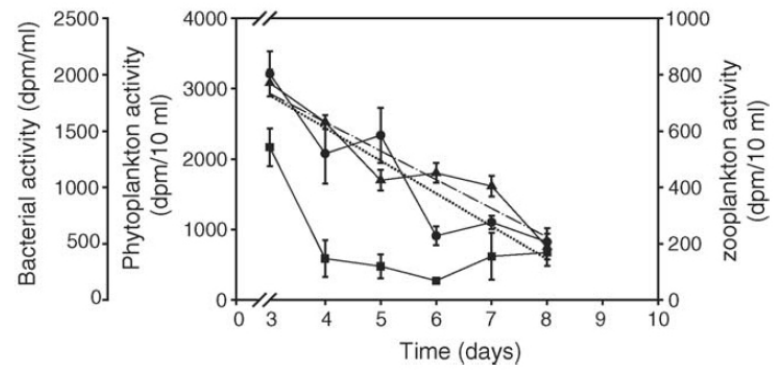

Figure 3. Means of phytoplankton activity $(\bullet)$, bacterial activity $(\mathbf{\Delta})$ and zooplankton activity ( $\mathbf{a})$ in control communities during the course of the experiment. Error bars are 95\% confidence intervals (n $=3$ ). Fitted lines are linear regression of bacteria (dashed) and phytoplankton (dotted) activity. of normalized data and yielded a percentage value to describe how similar the levels of all three integrated functional variables are to the controls for each treatment and each day. Finally, the similarities of the treatments from each day could be tested for significant differences by standard two-way ANOVA with time and treatment as fixed factors and Tukey's test as a post hoc test (Smith and Mercante, 1989). In all statistical analyses differences were defined to be significant when $p=$ 0.05 and marginally significant when $0.05<p \leq 0.1$.

\section{Results}

\subsection{Control mesocosms}

The concentration of chlorophyll a in the control communities was highest on Day $0(5.2 \mu \mathrm{g} / \mathrm{l})$, and significantly lower in the following 3 days (ANOVA and Dunnett's test, $p<0.05)$. Chlorophyll concentrations on Days 4 and 5 were not significantly different from Day 0, but decreased again for Days 7 and 8 (Figure 2).

The total community incorporation of ${ }^{14} \mathrm{C}$ labelled bicarbonate by phytoplankton was highest in control communities $(3,210 \mathrm{dpm} / 10 \mathrm{ml}$ ) on Day 3 (Figure 3), decreasing linearly through the experiment (linear regression, $p=0.012, R^{2}=0.83$ ). The specific response of the phytoplankton calculated as ${ }^{14} \mathrm{C}$ incorporation $/ \mu \mathrm{g}$ Chl a showed a high activity to begin with on Day 3 $\left(119 \times 10^{3} \mathrm{dpm} / \mu \mathrm{g} \mathrm{Chl} \mathrm{\alpha )}\right.$, after which it decreased to a minimum on Day $6\left(25 \times 10^{3} \mathrm{dpm} / \mu \mathrm{g}\right.$ Chl a), increased to a maximum on Day $7\left(197 \times 10^{3} \mathrm{dpm} / \mu \mathrm{g}\right.$ Chl a), and on Day 8 the specific activity was back to minimum. Bacterial activity also decreased linearly during the course of the experiment (linear regression, $p=0.004$, $\left.R^{2}=0.9\right)$ with values from $1,930 \mathrm{dpm} / 10 \mathrm{ml}$ on Day 3 to a minimum value of $500 \mathrm{dpm} / 10 \mathrm{ml}$ on Day 8 . Total zooplankton grazing declined more quickly from 540 $\mathrm{dpm} / 10 \mathrm{ml}$ on Day 3 reaching a steady level around $100 \mathrm{dpm} / 10 \mathrm{ml}$ already on Day 4, where it remained for the duration of the experiment.

The concentrations of inorganic nutrients $\left(\mathrm{SiO}_{2}{ }^{2}\right.$,

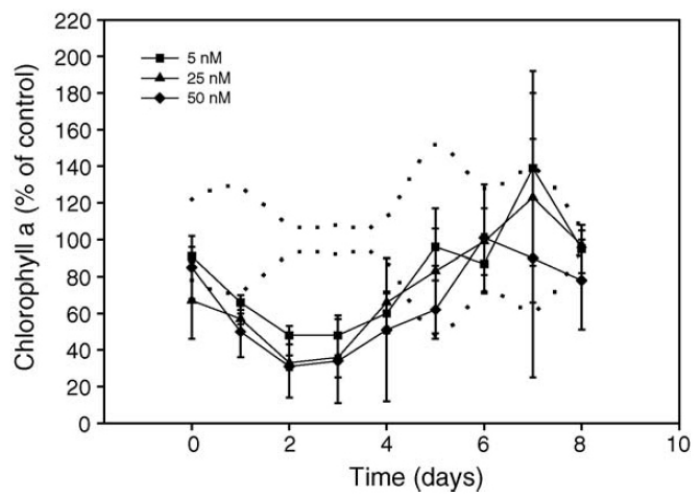

Figure 4. Concentrations of chlorophyll a in exposed communities as $\%$ of control. Dotted lines represent $95 \%$ confidence limits of control values and error bars are $95 \%$ confidence intervals $(n=3)$. 


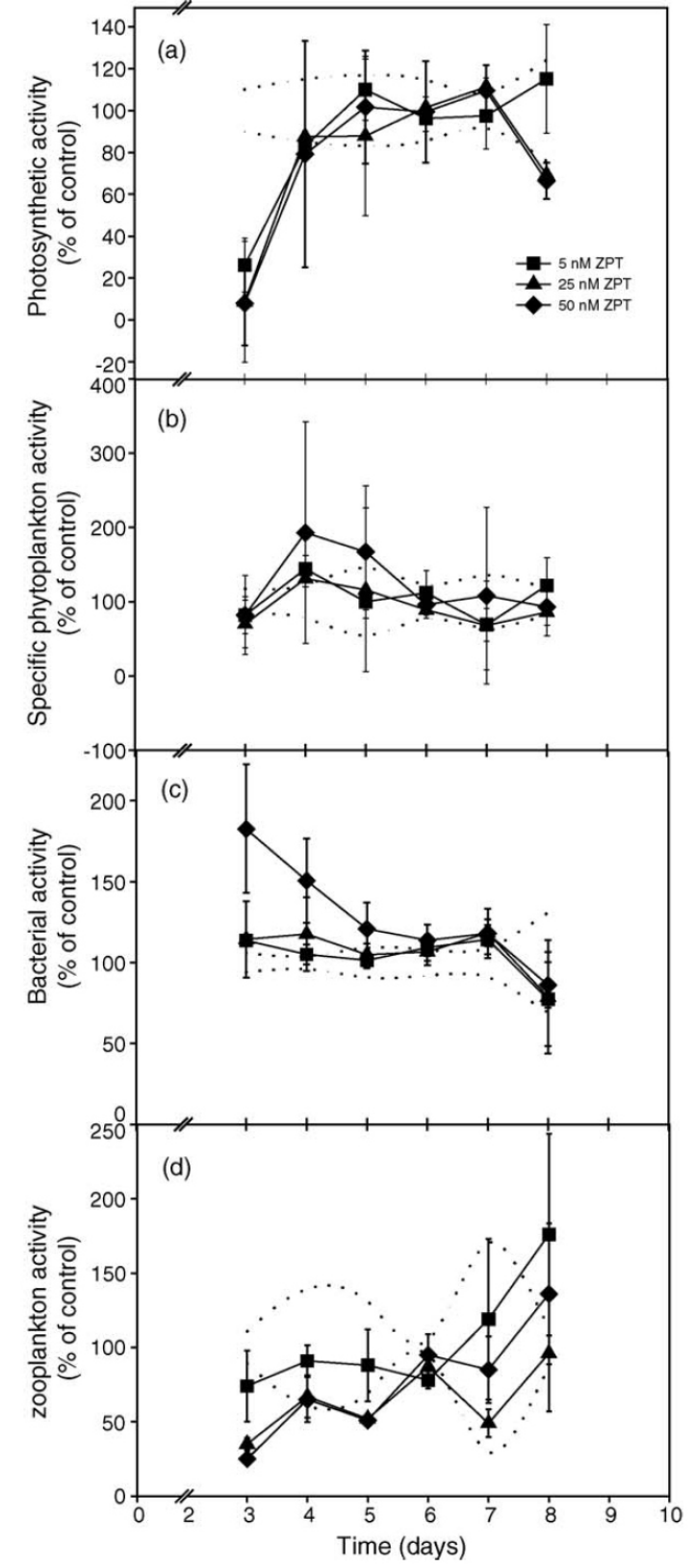

Figure 5. Response of (a) phytoplankton activity, (b) specific phytoplankton activity $\left({ }^{14} \mathrm{C}\right.$ incorporation per microgram Chlorophyll $\left.\mathrm{a}\right)$, (c) bacterial activity and (d) zooplankton activity in exposed communities as \% of control. Dotted lines represent $95 \%$ confidence limits of control values and error bars are standard deviations $(n=3)$.

$\mathrm{HPO}_{4}{ }^{2-}, \mathrm{NH}_{4}{ }^{+}, \mathrm{NO}_{3}{ }^{-}$) in the control mesocosms were closely linked to the development of chlorophyll a concentrations (Figure 2). They all decreased from the beginning on Day 0 and reached a temporary minimum on Day $3\left(\mathrm{SiO}_{2}^{2-:}: 11 \mu \mathrm{M}, \mathrm{HPO}_{4}^{2-:} 0.3 \mu \mathrm{M}, \mathrm{NH}_{4}^{+}\right.$: n.d., $\left.\mathrm{NO}_{3}^{-}: 0.1 \mu \mathrm{M}\right)$. All of them, except $\mathrm{HPO}_{4}^{2-}$, increased to a peak on Day 5 on which maximum concentrations were measured. A sharp decline in nutrient concentrations then followed towards minimum levels on Day 8. Phosphate concentrations increased from Day 3 to
Day 6 and eventually decreased on the last 2 days of the experiment.

\subsection{Exposed mesocosms}

Chlorophyll a concentrations were significantly lower $(p<0.05)$ in all treatments compared to the control from Day 1 to Day 3 and on Day 4 for $50 \mathrm{nM}$ treatments, but from Day 5 to the end of the experiment there were no significant differences in chlorophyll a concentrations among treatments (Figure 4).

Phytoplankton activity was also significantly lower $(p$ $<0.01$ ) on Day 3 for all three exposure concentrations (Figure 5a). The activity in the $5 \mathrm{nM}$ mesocosm bags was $38 \%$ of the activity in the control mesocosm, and in the 25 and $50 \mathrm{nM}$ mesocosms it was reduced to $23 \%$ of the control activity. The ICp approach yielded an $\mathrm{EC}_{50}$ value of $4.03 \pm 0.16 \mathrm{nM}$ ZPT on Day 3 for phytoplankton activity.

The phytoplankton activity of all the exposed communities increased towards control levels during the middle of the experimental period, but on the last day the activity levels of the exposed mesocosms began to show deviations from the control mesocosms again, although not significantly. In the 25 and $50 \mathrm{nM}$ mesocosms, phytoplankton activity was 69 and $66 \%$ of controls, whereas activity in the $5 \mathrm{nM}$ mesocosms was $115 \%$ of controls. The phytoplankton specific activity, measured as ${ }^{14} \mathrm{C}$ incorporation per microgram Chlorophyll a (Figure 5b), showed an increasing tendency in all exposed communities from Day 3 to Day 4, and for the $50 \mathrm{nM}$ exposed mesocosm bags the tendency was sustained until Day 5. At the end of the experiment, specific activity levels were lower or similar to control levels again.

An opposite development occurred in bacterial activity compared to the pattern observed in the functional response of the other two groups (Figure 5c). A dramatically higher bacterial activity was seen on Day 1 in the $50 \mathrm{nM}$ ZPT exposed communities, in which bacterial activity was $180 \%$ of control levels $(p<0.05)$. During the course of the next 4 days, this high activity level dropped to similar levels as that of the other exposed communities and controls. At the end of the experiment, the activity of the exposed mesocosm bags started to deviate from the control, illustrated by a marginally significant difference between $5 \mathrm{nM}$ exposed communities and controls $(p<0.1)$ with a reduction in bacterial activity to $73 \%$ of controls. A tendency towards a lower activity of the 25 and $50 \mathrm{nM}$ exposed communities on Day 8 compared to the controls was evident, with values of 77 and $91 \%$, respectively, but these differences were not statistically significant.

Zooplankton grazing levels were also severely impacted on Day 3, $24 \mathrm{~h}$ after the last addition of ZPT (Figure $5 d$ ). Grazing was $74 \%$ of control levels in the 


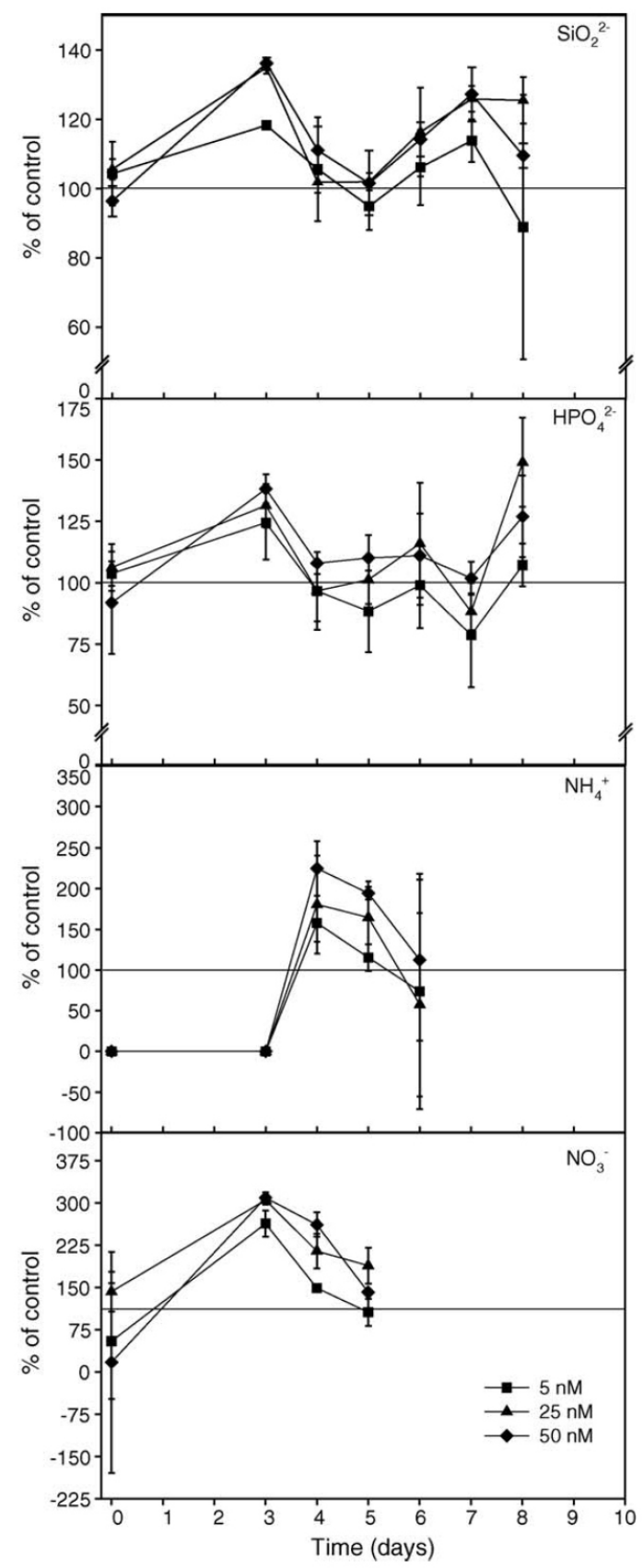

Figure 6. Response of inorganic nutrients in exposed communities as $\%$ of control. Error bars represent 95\% confidence intervals $(n=3)$.

mesocosms exposed to $5 \mathrm{nM} \mathrm{ZPT}$, and in the 25 and 50 $\mathrm{nM}$ exposed mesocosm bags, grazing was reduced significantly $(p<0.01)$ to 35 and $25 \%$, respectively. A calculation of $\mathrm{EC}_{50}$ yielded a value of 17 ( \pm 3 S.D.) nM ZPT on Day 3. On Day 5 the grazing level of exposed communities at 25 and $50 \mathrm{nM}$ was still significantly different from control communities $(p<0.05)$. At the end of the experiment, grazing levels in the exposed communities appeared to be higher than in the control communities again, but the differences were not stastistically significant. Mean grazing levels of the exposed communities on this day increased to as much as $176 \%$ $(5 \mathrm{nM})$ and $136 \%(50 \mathrm{nM})$ of control community grazing levels.

Generally the nutrient dynamics in the exposed mesocosms did not deviate from those of the control mesocosms, but the magnitude of changes was different (Figure 6). The exposed communities had significantly higher concentrations of all nutrients after ZPT exposure on Day $3\left(\mathrm{SiO}_{2}^{2-}, \mathrm{HPO}_{4}^{2-}\right.$, and $\left.\mathrm{NO}_{3}^{-}\right)$and on Day $4\left(\mathrm{NH}_{4}^{+}\right)$. At the end of the experiment, the concentrations of $\mathrm{SiO}_{2}{ }^{2-}$ and $\mathrm{HPO}_{4}{ }^{2-}$ were higher than the concentrations in the control communities, whereas the concentrations of $\mathrm{NH}_{4}^{+}$and $\mathrm{NO}_{3}^{-}$went below detection limits from Day 7 and Day 5, respectively. More specifically, the concentrations of silicate in the exposed communities increased to levels of 118, 135 and 136\% compared to the control communities, after which they fell to control levels on Day 5. On Day 8 silicate concentrations in the 25 and $50 \mathrm{nM}$ exposed communities were significantly higher than the control community concentrations $(126 \%, 110 \%)$.

Phosphate concentrations were significantly higher than the control concentrations on Day 3 for all three levels of exposed communities (124, 131, 138\%), from Day 4 to Day 7 they were fluctuating around control levels and ended at higher levels than control communities on Day $8(107,127,149 \%)$.

\subsection{PICT analysis}

On the final day of the experiment, a pollution induced community tolerance (PICT) study was carried out on selected duplicate mesocosm bags of all treatments on bacterial and phytoplankton activity. For the phytoplankton communities, significantly higher $\mathrm{EC}_{40}$ and $\mathrm{EC}_{20}$ values were calculated for the $50 \mathrm{nM}$ ZPT exposed communities compared to the communities exposed to lower ZPT concentrations and the control community (Table 1). The phytoplankton activity did not decrease below $50 \%$ of controls, not allowing the calculation of an $\mathrm{EC}_{50}$ value.

There was no indication of changing $\mathrm{EC}_{x x}$ values in PICT analyses of bacterial activity with no significant differences. The communities exposed to $5 \mathrm{nM}$ ZPT had a high $\mathrm{EC}_{50}$ value of $14 \pm 10 \mathrm{nM}$, but that trend was not visible in the $\mathrm{EC}_{40}$ and $\mathrm{EC}_{20}$ values.

\subsection{Bacterial diversity}

The genetic composition of the bacterial community was investigated more closely in control and $50 \mathrm{nM}$ ZPT exposed mesocosm bags. DGGE gels of the selected bags $(n=2)$ show that the diversity was the same in control and exposed bags at the beginning of the experiment (Figure 7). However, on Days 3 and 4 additional bands appeared in the exposed bags, which were not present in control bags. On Day 6 and for the 
Table 1

$\mathrm{EC}_{x x}$ values from PICT analyses performed on Day 8 of the experiment and calculated by the ICp approach (US EPA)

Pre-treatment (nM ZPT) $\quad \mathrm{EC}_{x y}$ values in $\mathrm{nM}$ ZPT \pm standard deviation

\begin{tabular}{rccllll} 
& \multicolumn{5}{l}{ Phytoplankton activity } & \multicolumn{3}{l}{ Bacterial activity } \\
0 & $\mathrm{EC}_{50}$ & $\mathrm{EC}_{40}$ & $\mathrm{EC}_{20}$ & $\mathrm{EC}_{50}$ & $\mathrm{EC}_{40}$ & $\mathrm{EC}_{20}$ \\
5 & $95 \pm 37$ & $74 \pm 27$ & $4 \pm 21$ & $5 \pm 7$ & $4 \pm 1.6$ & $2 \pm 0.2$ \\
25 & $59 \pm 17$ & $40 \pm 18$ & $3 \pm 12$ & $14 \pm 10$ & $4 \pm 3.8$ & $2 \pm 0.4$ \\
50 & $49 \pm 26$ & $38 \pm 7$ & $7 \pm 9$ & $4 \pm 4$ & $3 \pm 0.3$ & $2 \pm 0.2$ \\
& - & $184 \pm 37$ & $79 \pm 19$ & $5 \pm 3$ & $4 \pm 0.4$ & $2 \pm 0.2$
\end{tabular}
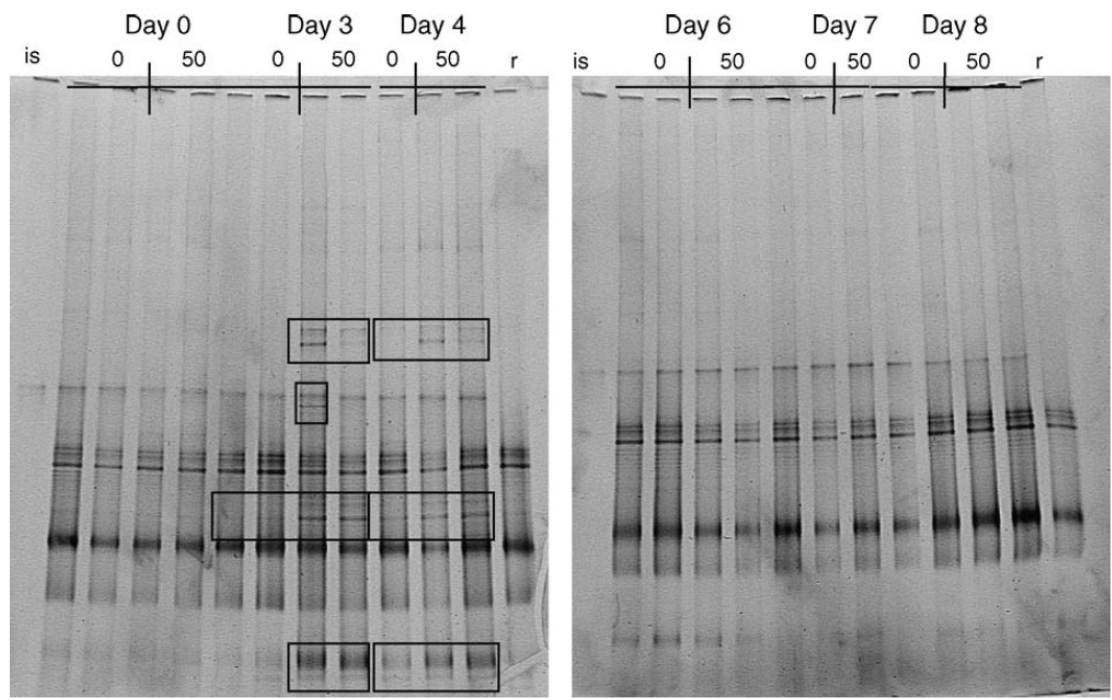

Figure 7. DGGE gels showing the genetic composition of bacterial communities in non-exposed (0) and 50 nM exposed communities (50) on selected days. Each lane is one mesocosm bag, and the same bags are shown for each day. Notice newly appearing bands on Days 3 and 4 indicated by frames. Internal standard (is); reference sample (r).

rest of the selected samples, the additional bands disappeared, and the band patterns of exposed and nonexposed communities were again similar.

3.5. Integrated community response

When all the functional variables for the three different communties are integrated in a multivariate analysis it provides a measure of total system function, including the relationship between the different trophic

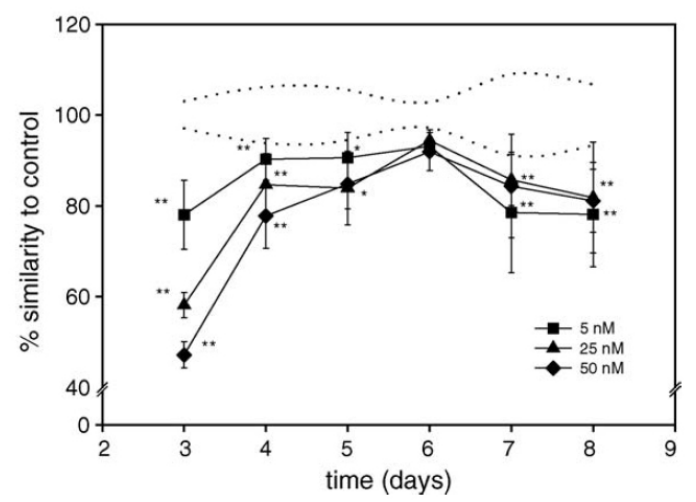

Figure 8. Integrated functional activity of exposed communities expressed as their Bray-Curtis similarity index (\% similarity to control communities). Grey lines are $95 \%$ confidence limits of control values. Asterisks denote statistical significance levels of $p<0.05\left({ }^{* *}\right)$ and $p<0.1\left({ }^{*}\right)$. Error bars are standard deviation $(n=3)$. levels at each time (Figure 8). The total system function was significantly different from the control in all the exposed bags on Days 3 and 4 (Dunnett's test, $p<$ 0.05). On Day 5 the similarity of the exposed systems' function to the controls was marginally different (Dunnett's test, $p<0.1$ ), and on Day 6 there was no significant difference between the exposed communities and the controls. However on Days 7 and 8, there was again a significant difference in functional levels (Dun-

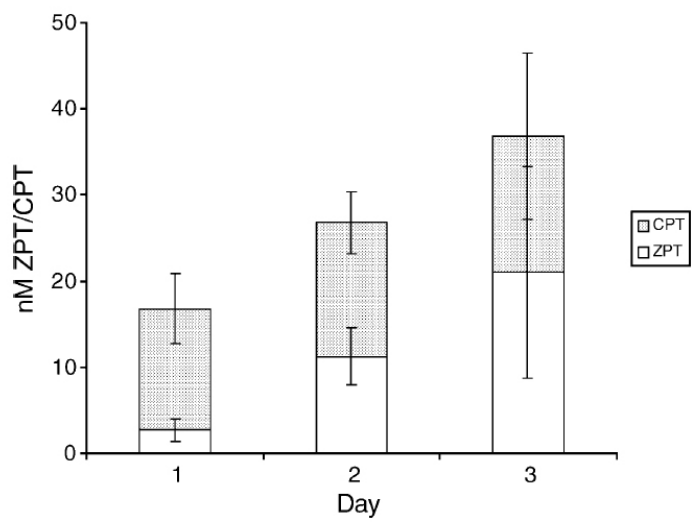

Figure 9. Actual concentrations of ZPT and CPT in mesocosm bags to which was added the highest nominal concentration of $50 \mathrm{nM} \mathrm{ZPT}$ on the first 3 days of the experiment. Additions of ZPT were performed at night on Days 0,1 and 2. Error bars are standard deviations. 
nett's test, $p<0.05)$. Tukey's test performed between treatments for each day showed a significant difference $(p<0.05)$ between all treatments on Day 3, between 5 and $50 \mathrm{nM}$ on Day 4, and a marginally significant difference $(p<0.1)$ between 5 and $25 \mathrm{nM}$ on Day 5 . For the remaining duration of the experiment, there was no significant difference between the different exposures in the integrated community response.

\subsection{FATE of ZPT}

Zinc- and copper-pyrithione were measured in all three replicate bags with the highest nominal concentration of $50 \mathrm{nM}$ directly after each of the three additions. The nominal concentration of ZPT was not achieved on any of the days, nor when the concentrations of ZPT and CPT were combined (Figure 9). The highest ZPT $+\mathrm{CPT}$ concentration of $37 \mathrm{nM}$ was reached after the third addition. There was a trend with increasing total ZPT/CPT concentration for every addition, and towards a larger fraction of ZPT of the total.

\section{Discussion}

The high production in the initial phase of the mesocosm experiment depleted nutrients from the water column, leading to a decrease in phytoplankton activity, and also a general sedimentation in the bags due to reduced turbulence in the mesocosm bags compared to open water. Potential nutrient limitation in a marine system can be predicted when inorganic nutrient concentration and certain concentration ratio criteria are fulfilled (Dortch and Whitledge, 1992). In accordance with such criteria (DIN $<2 \mu \mathrm{M}, \mathrm{N}: \mathrm{P}<10$ and Si:N > $1)$, there was a clear indication of nitrogen limitation in all mesocosm bags throughout the experimental period. This was also confirmed in nutrient enriched dilution experiments conducted with samples from control mesocosm bags (Henriksen, pers. com.). This has implications for the activity levels in the communities and how functional groups may dominate and interact, and it may be argued that the observed responses to the toxicant exposure are influenced by these multistress conditions (Vinebrooke et al., 2004). On the oth-

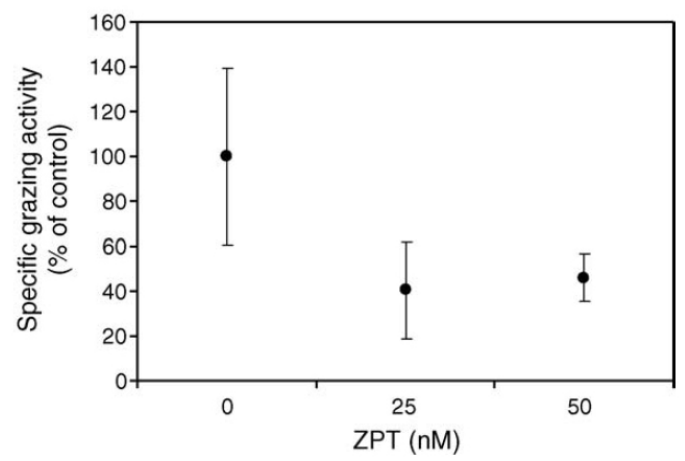

Figure 10. Specific zooplankton activity as \% of control on Day 3 of the experiment. Error bars are standard deviations. er hand nitrogen limitation is a frequent occurrence in coastal marine systems and part of a natural seasonal cycle, and therefore the results of this study are ecologically relevant.

In spite of nutrient limitation and sedimentation it was possible to distinguish direct effects of ZPT on the functional variables (Figure 5). Severe reductions in phytoplankton activity, grazing activity of zooplankton and bacterial activity were evident on Day 3 of the experiment with $\mathrm{EC}_{50}$ values of $16-18 \mathrm{nM}$ nominal concentrations of ZPT.

The initial effects on phyto- and zooplankton were still evident on Day 4, which was the fourth day after the first addition of ZPT. The initial reduction of phytoplankton activity is consistent with recent studies of the effects of ZPT on natural communities of bacteria and phytoplankton (Maraldo and Dahllöf, 2004a,b), that demonstrated serious effects on protein synthesis and phytoplankton activity with generally low $\mathrm{EC}_{50}$ values and high seasonal variation in responses.

The effect on zooplankton grazing activity could be due to an indirect effect of reduced prey availability as well as a direct effect, where the same number of individuals has a lower prey uptake. Adjusting the grazing to abundance of adults and copepodites shows that the specific activity of zooplankton as the grazing/individual also decreased (Figure 10), which suggests that the decrease was due to direct effects.

The consequences of these changes to the community at the beginning of the study are, among others, a fourfold reduction of total grazing activity. This may have consequences for the phytoplankton community structure indirectly, because alterations in predation pressure may change size of algae or diversity of phytoplankton. For the state of the zooplankton community itself, there are also serious implications of a fourfold reduced food uptake. Lower assimilation of energy leads to decreased growth, lower egg production by females and possible additive effects from other stressors (Berggreen et al., 1988; Kiørboe and Nielsen, 1994; Sibly et al., 2000).

The slower decrease of nutrients in exposed communities compared to control communities may correlate with a higher degradation of algal cells and a subsequently higher bacterial activity in the exposed communities. This was especially evident in the communities exposed to the highest concentrations of ZPT, where bacterial activity was $180 \%$ of control levels on Day 3. The increase in bacterial activity was unexpected on the basis of laboratory experiements which have shown bacteria to be even more sensitive to ZPT than phytoplankton (Maraldo and Dahllöf, 2004a). It is likely that a negative response on the bacteria occurred right after the first addition of ZPT, but since bacterial turnover is much more rapid than phytoplankton turn- 
over, a recovery of the bacterial community from the direct impact was probably dominated by fast growing opportunistic species and not by toxicant sensitive species. The molecular analyses of the genomic diversity of the bacteria in the $50 \mathrm{nM}$ addition showed appearance of some species in the beginning of the experiment not observed in control bags, which is consistent with this hypothesis. The fast growing species could be tolerant species, but the PICT data do not suggest tolerance, since it showed little or no changes in tolerance.

The nominal concentrations were not achieved at any of the additions. This is partly due to that the actual volume was not the 3,000 1 that the calculations were based on, but rather varied between 2,500 and 3,000 1 . The analysis of the fate of ZPT showed a transformation of ZPT to the more stable CPT, with an average of $15 \mathrm{nM}$ CPT each day. This suggests that the free copper concentration remained the same on all 3 days, whereas there was a reduction in the availability of other weaker complex binding ligands, which led to an increase in ZPT concentration with time. This is consistent with the increased sedimentation and reduction in $\mathrm{Chl} \mathrm{a}$, and with previous studies on the fate of ZPT in seawater (Grunnet and Dahllöf, 2005). The presence of other ligands that could complex $\mathrm{Zn}$ is an additional reason for not reaching the attempted nominal concentrations. Although the concentration was only measured in the highest addition, the variation in fate of ZPT within each addition is likely to have been of the same magnitude. This variation in exposure within a nominal concentration is thereby likely to cause some of the variation in the response variables observed within the respective additions.

For the pelagic ecosystem as a whole, there is the issue of exposure level and time in relation to effect size. If the exposure to ZPT is continuous, as is highly possible in reality, and not restricted to three pulse exposures of small nominal concentrations as in this study, such effects as observed here may underestimate the effects in natural environments. However, the transchelation of ZPT to CPT, and of ZPT to unidentified $\mathrm{Zn}$ complexes, means that the fate of ZPT in the environment will differ from place to place and time to time, due to the differences in the availability of $\mathrm{Cu}$ and organic ligands. Thereby the effects of ZPT can also vary accordingly.

The phytoplankton PICT study indicated that the nominal concentration of $50 \mathrm{nM}$ ZPT induced a more tolerant phytoplankton community compared to the control. Community tolerance develops when the more sensitive components of the community are eliminated or severely affected, while the other less sensitive components survive. This means that tolerance only will be induced if the toxicant concentration lies with- in the sensitivity span of the community, i.e. the range of toxicant concentration, over which the community can survive and adapt. Concentrations that are sufficiently low allow all components of the community to exert resilience and will not lead to tolerance development. If a higher concentration is applied, where most of the community components are severely affected, then the sensitivity and composition of the community after exposure will depend on the succession rate of the individual components rather than on their relative tolerance. We suggest that the highest nominal addition of $50 \mathrm{nM}$ ZPT used in the study correspond to the sensitivity span of the phytoplankton, thereby inducing tolerance, whereas the nominal concentrations of 5 and $25 \mathrm{nM}$ ZPT resulted in sufficiently low true concentrations to which the community was resilient. For the bacterial community however, the additions $>5 \mathrm{nM}$ exceeded their sensitivity range affecting all components thereby not inducing tolerance. It cannot be ruled out that the lack of tolerance induction may also be due to a question of time since impact from ZPT and an earlier occurrence of tolerance. There may have been a tolerance increase up until Day 4, indicated by the new bands from Days 3 and 4 on the DGGE gels, which did not persist to the end of the experiment, where the PICT analysis was done. With the available data it is not possible to distinguish between a shift toward tolerance or toward opportunistic species in the bacteria.

The additions of ZPT caused major changes in the integrated community function in the beginning of the experiment, due to direct impacts such as a reduction in biomass and activity of phytoplankton. The change was not only a change from control communities but also between the three levels of exposure in the first 3 days. At the end of the experiment the integrated community function in the exposed communities started to deviate from control again, suggesting that a shift in community structure and function had occurred. The effect of ZPT thereby caused a system change that lasted longer than the initial direct toxic effect. The effect on the integrated function shows that it is the relation between the activity of the different trophic groups that is different from the control at the end of the experiment, and also that there is a different response between the exposure levels. The low addition shows tendencies towards higher phytoplankton and grazing activities and reduced bacterial activity, whereas the higher additions have lower phytoplankton and bacterial activity combined with a higher grazing activity.

\section{Conclusion}

This experiment provided evidence of diverse effects on the functions of marine plankton communities from ZPT. Direct effects were immediately observed, lead- 
ing to cascading indirect effects throughout the community, which eventually caused different developments in the integrated function of the ecosystem. This study shows that even under short pulse exposures of a rapidly degradable pollutant at relatively low concentrations, the plankton community was affected significantly. It is likely that continuous exposure to ZPT could lead to long-term effects, even though ZPT itself has a short half-life, thereby causing more permanent changes in structure and function than observed using pulse exposure. It also demonstrates that it is possible to assess the functional effects of a stressor in a complex mesocosm system, and to determine effects in a complex plankton community, which were not predictable from laboratory studies.

\section{Acknowledgements}

This work was funded by a Ph.D. fellowship from Roskilde University and National Environmental Research Institute, Dep. Marine Ecology. We would like to say thank you to Kim Gustavsson, DHI, Katarina Abrahamsson \& Ellinor Svensson, University of Göteborg, the staff at Sømine field station and Gitte Jacobsen, Dorete W. Jensen Peter Henriksen and Jeanette Blidorf from NERI for practical help.

\section{References}

Andersen, J., S.S. Markager, and G. Ærtebjerg, 2004. Tekniske anvisninger for marin overvågning. vandkemiske parametre 2.2.

Berggreen, U., B.W. Hansen, and T. Kiørboe, 1988. Food size spectra, ingestion and growth of the copepod Acartia-tonsa during development-implications for determination of copepod production. Mar. Biol. 99(3): 341-352.

Blanck, H., S.-A., Wängberg, and S. Molander, 1988. Pollution-induced community tolerance-a new ecotoxicological tool. ASTM STP 988: 219-230.

Bray, J.R., and J.T. Curtis, 1957. An ordination of the upland forest communities of Southern Wisconsin. Ecol. Monogr. 27 (4): 326-349.

Calow, P., and V.E. Forbes, 1998. How do physiological responses to stress translate into ecological and evolutionary processes? Comp. Biochem. Physiol. A: Mol. Integr. Physiol. 120 (1): 11-16.

Clarke, K.R., and R.M. Warvick, 1994. Change in Marine Communities: An Approach to Statistical Analysis and Interpretation. National Environment Research Council, U.K.

Dahllöf, I., H. Blanck, P.O.J. Hall, and S. Molander, 1999. Long-term effects of tri- $n$-butyl-tin on the function of a marine sediment system. Mar. Ecol. Prog. Ser. 188: 1-11.

Dahllöf, I., K. Grunnet, R. Haller, M. Hjorth, K. Maraldo, and D.G. Petersen, 2005. Analysis fate and toxicity of zinc-and copper-pyrithione in the marine environment. TemaNord, 550.

Dortch, Q., and T.E. Whitledge, 1992. Does nitrogen or silicon limit phytoplanktpon production in the Mississippi River Plume and nearby regions. Continental Shelf Res. 12 (11): 1,293-1,309.

Fleeger, J.W., K.R. Carman, and R.M. Nisbet, 2003. Indirect effects of contaminants in aquatic ecosystems. Sci. Total Environ. 317 (13): 207-233.
Grubbs, F.E., and G. Beck, 1972. Extension of sample sizes and percentage points for significance tests of outlying observations. Technometrics 14 (4): 847.

Grunnet, K., and I. Dahllöf, 2005. Environmental fate of the antifouling compound zinc-pyrithione in seawater. Environ. Toxicol. Chem. 24: 301-306.

Hjorth, M., R. Haller, and I. Dahllöf, in press. The use of ${ }^{14} \mathrm{C}$ tracer technique to assess the functional response of zooplankton community grazing to toxic impact. Mar. Environ. Res.

Kiørboe, T., and T.G. Nielsen, 1994. Regulation of zooplankton biomass and production in a temperate, coastal ecosystem. 1. Copepods. Limnol. Oceanogr. 39 (3): 493-507.

Maraldo, K., and I. Dahllöf, 2004a. Seasonal variations in the effect of zinc pyrithione and copper pyrithione on pelagic phytoplankton communities. Aquat. Toxicol. 69 (2): 189-198.

Maraldo, K., and I. Dahllöf, 2004b. Indirect estimation of degradation time for zinc pyrithione and copper pyrithione in seawater. Mar. Poll. Bull. 48 (9/10): 894-901.

Mackie, D.S., C.M.G. van den Berg, and J.W. Readman, 2004. Determination of pyrithione in natural waters by cathodic stripping voltammetry. Anal. Chim. Acta 511: 47-53.

Møhlenberg, F., S. Petersen, K. Gustavson, T. Lauridsen, and N. Friberg, 2001. Mesocosm experiments in the approval procedure for pesticides. A literature study on effects of mesocosm characteristics and validity of extrapolation methods to protect sensitive species. Pesticides Res. (Danish EPA) 56.

Norberg-King, T.J., 1993. A Linear Interpolation Method for Sublethal Toxicity: The Inhibition Concentration (ICp) Approach. Version 2.0. National Effluent Toxicity Assessment Center. Technical Report 0393. United States Environmental Protection Agency.

Paerl, H.W., J. Dyble, L. Twomey, J.L. Pinckney, J. Nelson, and L. Kerkhof, 2002. Characterizing man-made and natural modifications of microbial diversity and activity in coastal ecosystems. Antonie Van Leeuwenhoek Int. J. Gen. Mol. Microbiol. 81: 487-507.

Petersen, D.G., I. Dahllöf, and L.P. Nielsen, 2004. Effects of zinc pyrithione and copper pyrithione on microbial community function and structure in sediments. Environ. Toxicol. Chem. 23(4): 921-928.

Preston, B.L., 2002. Indirect effects in aquatic ecotoxicology: implications for ecological risk assessment. Environ. Man. 29(3): 311-323.

Sibly, R.M., T.D. Williams, and M.B. Jones, 2000. How environmental stress affects density dependence and carrying capacity in a marine copepod. J. Appl. Ecol. 37(3): 388-397.

Smith, E.P., and D. Mercante, 1989. Statistical concerns in the design and analysis of multispecies microcosm and mesocosm experiments. Tox. Assess. 4(2): 129-147.

Smith, D.C., and F. Azam, 1992. A simple, economical method for measuring bacterial protein synthesis rates in seawater using $3 \mathrm{H}-$ leucine. Mar. Microbial. Food Webs 6: 107-114.

Thomas, K.V., 1999. Determination of the antifouling agent zinc pyrithione in water samples by copper chelate formation and high-performance liquid chromatography-atmospheric pressure chemical ionisation mass spectrometry. J. Chromatogr. A 833: 105109.

Vinebrooke, R.D., K.L. Cottingham, J. Norberg, M. Scheffer, S.I. Dodson, S.C. Maberly, and U. Sommer, 2004. Impacts of multiple stressors on biodiversity and ecosystem functioning: the role of species co-tolerance. Oikos 104: 451-457. 